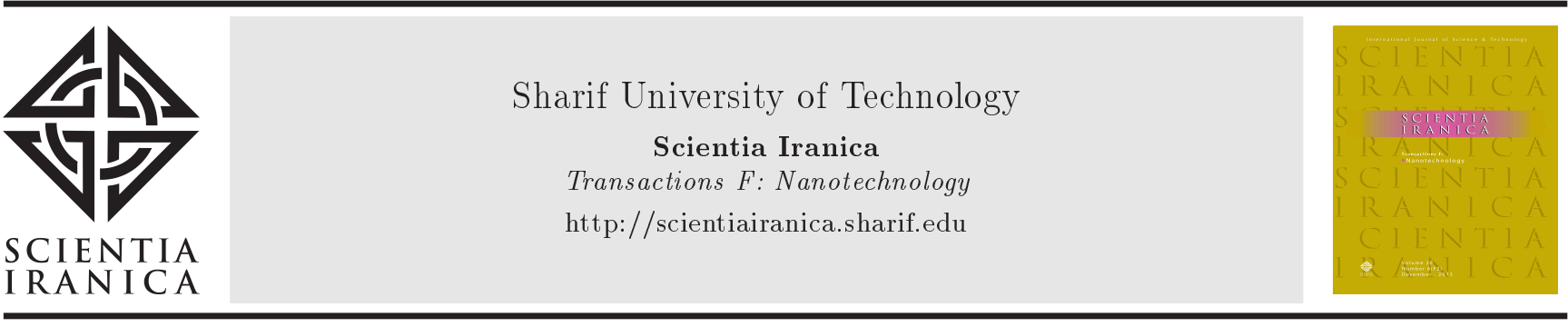

Research Note

\title{
Study of anticorrosion properties of epoxy-nano alumina/nano chitosan nanocomposite coating
}

\author{
N. Feizi and H.R. Ghorbani* \\ Department of Chemical Engineering, Qaemshahr Branch, Islamic Azad University, Qaemshahr, Iran.
}

Received 6 January 2021; received in revised form 5 April 2021; accepted 17 May 2021

\section{KEYWORDS}

Anticorrosion;

Nano alumina;

Nano chitosan;

Coating;

Epoxy.

\begin{abstract}
In this research, the anticorrosion properties of epoxy-based nanocomposite coating were studied using the Taguchi statistical method. An L16 orthogonal array with four control factors at four levels and two iterations was employed to prepare nanocomposite coating by adding chitosan nanoparticles and alumina nanoparticles in different conditions including concentrations, temperatures, and mixing times. The analysis of variance and signal-to-noise ratio demonstrated that applying film coating on steel panels could significantly enhance anticorrosion properties. The optimal conditions required for nanocomposite coating preparation were alumina nanoparticles $2 \%$, chitosan nanoparticles $2 \%$, temperature of $20^{\circ} \mathrm{C}$, and a mixing time of 30 minutes. Finally, the surface of the coated film was analyzed by SEM.
\end{abstract}

(C) 2021 Sharif University of Technology. All rights reserved.

\section{Introduction}

Due to the fast-paced growth of technology and industry, the application of anticorrosion coatings on surfaces exposed to corrosive materials has turned into a significant challenge. Anticorrosion coatings have been extensively applied to the maintenance of vehicles used by transportation agencies to protect a substrate through providing a barrier between the metal and the outside environment, especially in a chloride-laden environment. Protecting facilities and equipment from corrosion is as important as the manufacturing process. This issue gains significance in different industries such as oil, gas, petrochemical, and shipbuilding industries. Protection against corrosion using different coatings re-

\footnotetext{
* Corresponding author.

E-mail address: hamidghorbani6@gmail.com (H.R. Ghorbani)
}

doi: $10.24200 /$ sci. 2021.57421 .5233 mains a major challenge in recent years. Among metal, mineral, polymer, and hybrid coatings, polymer ones have been widely used due to their easy applications on surfaces and relatively low costs [1-3].

A number of metals and alloys such as aluminum and steel are usually used in the maintenance of vehicles of transportation agencies, which are often exposed to the risk of corrosion and economic loss. Some techniques including barrier protection, galvanization, and cathodic protection have been established to protect metals from corrosion [4,5]. The anticorrosion coatings have drawn considerable attention for many years due to their simplicity and efficiency. Corrosion coatings have been developed and tested to prevent the harmful effects of corrosion on metals [6-8]. Epoxy powder coatings have been widely used to protect metal substrates from corrosion. In this respect, different types of organic and inorganic pigments have been used to improve the anticorrosion performance of epoxy powder coatings. Owing to their excellent anticorrosion performance, Chromates have been widely employed 
Table 1. Factors and their levels: The study of the role of concentration, temperature, and mixing time of nanoparticles on the production of anticorrosion nano-coatings.

\begin{tabular}{ccccc}
\hline Factors & Level 1 & Level 2 & Level 3 & Level 4 \\
\hline Alumina nanoparticles concentration (wt\%) & 0.5 & 1 & 1.5 & 2 \\
Chitosan nanoparticles concentration (wt\%) & 0.5 & 1 & 1.5 & 2 \\
Temperature $\left({ }^{\circ} \mathrm{C}\right)$ & 20 & 30 & 40 & 50 \\
Mixing time $(\mathrm{min})$ & 2 & 5 & 15 & 30 \\
\hline
\end{tabular}

to improve the protection behavior of epoxy coatings. However, chromates are toxic and carcinogenic [911]. Zheludkevich et al. developed Mg-Al and ZnAl-LDH with a divanadate anion coating for corrosion protection of 2024 aluminum alloy. Incorporation of divanadate-doped $\mathrm{Zn}-\mathrm{Al}-\mathrm{LDH}$ to a commercial primer led to improved corrosion protection, and the final performance was found comparable to that of chromatebased coatings [12].

In another study, Leo and Wang investigated the effect of particles and nanoparticles on the properties of polymer coatings and proved that the application of filler mineral particles would enhance the mechanical properties and reduce the corrosion rate [13]. Alibakhshi et al. synthesized a Zn-Al-LDH nanostructure enclosed by phosphate ions that reduced the corrosion rate of steel by emitting phosphate ions [14]. Moreover, Ghorbani et al. synthesized $\mathrm{CuO}$ nanoparticles through which the permeability of polyurethane coatings was modified and the antibacterial properties of this coated film were investigated [15]. The main objective of this study was to prepare nanocomposite coatings to investigate the anticorrosion properties. To this end, epoxy resin, alumina nanoparticles, and chitosan nanoparticles were employed in different concentrations and their corresponding corrosion rates were measured.

\section{Material and methods}

\subsection{Materials}

In the present study, alumina nanoparticles $(20-40 \mathrm{~nm})$ and chitosan nanoparticles (20-40 nm) were purchased from Nanotech Company (India) for coating purposes. Epoxy resin was purchased from Shargh Chemical Company (Iran).

\subsection{Design Of Experiments (DOE)}

An L16 orthogonal array with four factors of control at four levels and two interactions was employed to prepare nanocomposite coating by adding chitosan nanoparticles and alumina nanoparticles with different concentrations, temperatures, and mixing times. Analysis of the laboratory results was carried out using Taguchi method and signal-to-noise analysis finally facilitated determining optimal conditions in terms of the mentioned factors. An orthogonal array was designed for experiments using Qualitek-4 software and four variables of alumina nanoparticle concentration, chitosan nanoparticle concentration, temperature, and mixing time, each at four different levels (Tables 1 and 2).

\subsection{Preparation of epoxy-based nanocomposite coating}

Experiments were performed based on the orthogonal array designed to prepare the nanocomposite coating by considering four variables including alumina nanoparticles concentration, chitosan nanoparticles concentration, temperature, and mixing time at four different levels (Table 2). In this process, 16 containers containing $100 \mathrm{ml}$ of epoxy resin were prepared. To each container were added alumina and chitosan nanoparticles based on the determined design and they were stirred for 5 minutes. The resulting solution was then sonicated for 10 minutes. Finally, a hardener with an appropriate ratio (epoxy/ hardener as 4:1) was added to each of the prepared solutions at different temperatures (Table 1), and the mixing process was carried out at different times according to Table 1. Next, the steel panels were cleaned with acetone and dried in a dryer for further use. The resulting solutions were sprayed directly onto the steel panels. The coated samples were then dried and prepared at room temperature for seven days. The thickness of the obtained film was approximately $60 \pm 5$ micrometers. In addition, Scanning Electron Microscopy (SEM) was employed to study the structure of the coated film.

\subsection{Corrosion measurement}

First, the steel panels prepared in the previous step were weighed and the obtained values were recorded for use in the next steps. Then, the $3.5 \% \mathrm{NaCl}$ aqueous solution was prepared. The prepared panels were placed in brine solutions and weighed again after 30 days, and the obtained values used for calculating corrosion rate (mpy) were recorded after 30 days.

\section{Results and discussions}

\subsection{Study of corrosion rate}

One simple way to estimate the corrosion rate is the immersion test. In this method, the metal is completely placed in a corrosive environment and then, based on the changes in the weight of the metal, its corrosion 
Table 2. Levels of each factor used in experiments to optimize the corrosion rate.

\begin{tabular}{ccccc}
\hline $\begin{array}{c}\text { Experiment } \\
\text { number }\end{array}$ & $\begin{array}{c}\text { Alumina } \\
\text { nanoparticles } \\
\text { concentration }\end{array}$ & $\begin{array}{c}\text { Chitosan } \\
\text { nanoparticles } \\
\text { concentration }\end{array}$ & Temperature & Mixing time \\
\hline 1 & 1 & 1 & 1 & 1 \\
2 & 1 & 2 & 2 & 2 \\
3 & 1 & 3 & 3 & 3 \\
4 & 1 & 4 & 4 & 4 \\
5 & 2 & 1 & 2 & 3 \\
6 & 2 & 2 & 1 & 4 \\
7 & 2 & 3 & 4 & 1 \\
8 & 2 & 4 & 3 & 2 \\
9 & 3 & 1 & 3 & 3 \\
10 & 3 & 2 & 4 & 2 \\
11 & 3 & 3 & 1 & 1 \\
12 & 3 & 4 & 2 & 2 \\
13 & 4 & 1 & 4 & 1 \\
14 & 4 & 2 & 3 & 4 \\
15 & 4 & 3 & 2 & 1 \\
16 & 4 & 4 & & 3 \\
\hline
\end{tabular}

Table 3. Corrosion rates for steel and epoxy coated steel.

\begin{tabular}{cc} 
Uncoated steel (control sample 1) & Epoxy coated steel (control sample 2) \\
\hline $6.87 \mathrm{mpy}$ & $5.18 \mathrm{mpy}$
\end{tabular}

rate (mpy) is determined by the following equation:

$$
m p y=\frac{543 W}{\rho A t},
$$

where $W$ is the weight loss in mg, $\rho$ the density of metal sample $\left(\mathrm{g} / \mathrm{cm}^{3}\right), A$ the exposed surface area (in. $\left.{ }^{2}\right)$, and $t$ the exposure time in hr. Table 3 shows the corrosion rates for steel (control sample 1 ) and epoxy resin coated steel (control sample 2).

According to Table 3, the corrosion rate for the uncoated steel panels is greater than 5 (mpy), indicating relatively high corrosion in these conditions; however, with a coating of epoxy resin without nanoparticles, the corrosion rate is reduced to 5.18 (mpy), which is indicative of a positive effect. Therefore, the steel panels coated with the epoxy resin (without nanoparticles) exhibited some degrees of corrosion. In case the mpy number is less than 5, the corrosion resistance is appropriate; otherwise, it is low. If this number is greater than 50 , the corrosion resistance is very poor. The weight loss of the panels was measured after 30 days in a $3.5 \% \mathrm{NaCl}$ aqueous solution. The corrosion rates were calculated in two replications from Eq. (1). The obtained results are shown in Table 4.

The output variable used in the statistical analysis is the corrosion rate, which is a measurable physical
Table 4. Corrosion rate after the preparation of nanocomposite film (two iterations).

\begin{tabular}{ccc}
\hline $\begin{array}{c}\text { Experiment } \\
\text { number }\end{array}$ & $\begin{array}{c}\text { mpy } \\
\text { (iteration 1) }\end{array}$ & $\begin{array}{c}\text { mpy } \\
\text { (iteration 2) }\end{array}$ \\
\hline 1 & 4.32 & 4.31 \\
2 & 4.14 & 4.13 \\
3 & 2.71 & 2.70 \\
4 & 2.57 & 2.57 \\
5 & 3.94 & 3.95 \\
6 & 3.40 & 3.41 \\
7 & 4.07 & 4.08 \\
8 & 3.36 & 3.35 \\
9 & 3.49 & 3.50 \\
10 & 3.73 & 3.72 \\
11 & 3.39 & 3.40 \\
12 & 3.97 & 3.96 \\
13 & 3.83 & 3.84 \\
14 & 4.18 & 4.19 \\
15 & 2.31 & 2.32 \\
16 & 2.40 & 2.39 \\
\hline
\end{tabular}

quantity. The signal-to-noise analysis was carried out in this study using $S / N$ ratio calculated by the following equation:

$$
(S / N)=-10 \log (M S D)
$$


where MSD is the Mean Squared Deviation defined by the following relation:

$$
M S D=\frac{\sum_{i=1}^{n}\left(y_{i}\right)^{2}}{n}
$$

where $n$ is the total number of repetitions of the experiment and $y_{i}$ is the result of each experiment. Figures 14 present the average of $S / N$ ratio at different levels of each factor in reducing the corrosion rate including alumina nanoparticle concentration, chitosan nanoparticle concentration, temperature, and mixing time.

Figure 1 shows the effect of alumina nanoparticle concentration on coated films at four levels to reduce the corrosion rate. According to this figure, the lowest corrosion rate for the panels was obtained at level 4 based on the concentration of alumina nanoparticles, i.e., the concentration of $2 \mathrm{wt} \%$. The difference between the lowest and highest $S / N$ ratios in this factor was about $16.5 \%$, indicating the relatively good effect of alumina nanoparticle concentration on reducing the corrosion rate of panels. In general, alumina nanoparticles provide excellent protection against corrosion. In case alumina nanoparticles are on the film surface, the corrosion rate can be well reduced; however, it is in the bulk (nanocomposite) and its effect on reducing the corrosion rate is insignificant. It was observed that upon increasing the concentration of alumina nanoparticles up to $2 \%$, the corrosion rate would decrease probably due to the presence of more alumina nanoparticles on the surface of the coated film. On the contrary, alumina nanoparticles play the role of nanofillers which reduce the corrosion rate due to better coating of the steel panel.

Figure 2 shows that the lowest corrosion rate for the panels obtained at level 4 based on the concentration of chitosan nanoparticles (the concentration of 2 wt\%). The difference in the $S / N$ ratio at levels 3 and 4 in this factor was about $1 \%$. Therefore, it exhibited a similar performance for concentrations of $1.5 \%$ (level 3 ) and $2 \%$ (level 4 ) in terms of reducing the

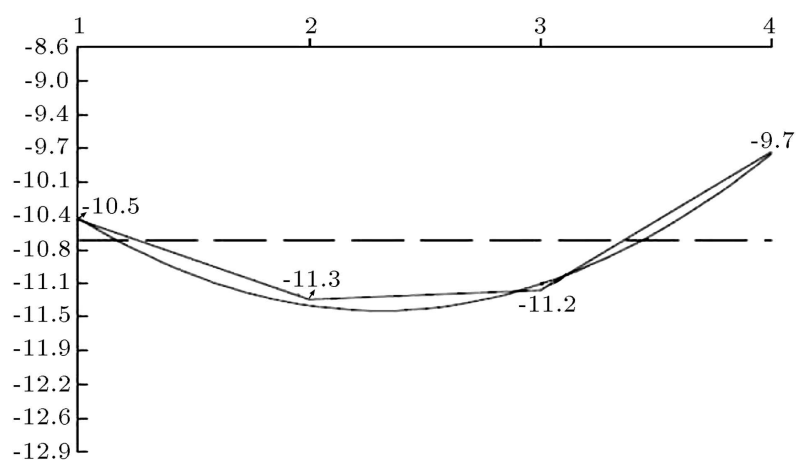

Figure 1. Average of $S / N$ ratio for different concentration levels of alumina nanoparticles used for reducing the corrosion rate.

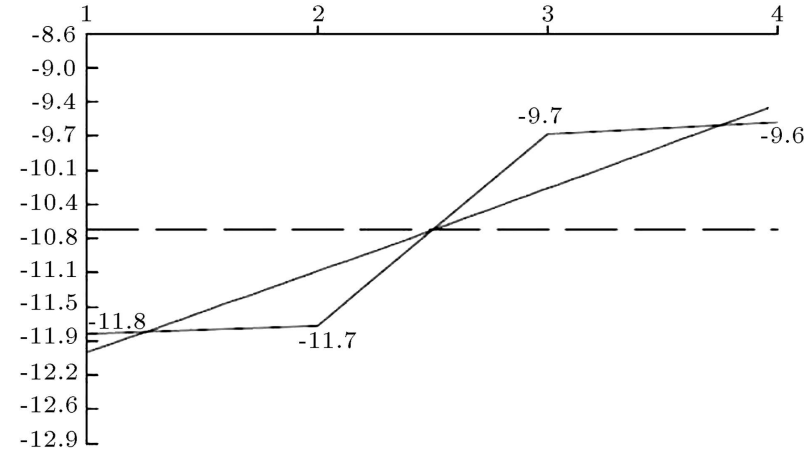

Figure 2. Average of $S / N$ ratio for different levels of chitosan nanoparticles concentration used for reducing the corrosion rate.

corrosion rate of steel panels. According to the software analysis, the highest rate of corrosion reduction was observed at level 4 and the optimal concentration for preparing the coating nanocomposite was about $1.5 \%$. A comparison between the two levels revealed a slight difference in reducing the corrosion rate. In addition, at lower concentrations, consumption of nanoparticles and, consequently, the costs were reduced. The chitosan nanoparticles act as a nanofiller reinforcing agent in epoxy polymer solution. The chitosan nanoparticles enhanced the anticorrosion properties of nanocomposite coated films.

According to Figure 3, temperature changes in preparation of coated films have negligible effect on the corrosion rate of the prepared panels. For the temperature factor, the difference between the lowest and highest corrosion rates for the panels was about $4.5 \%$ which, as a very small amount, was indicative of its negligible effect on preparing the film coating. Although the best temperature performance in reducing the corrosion rate of panels was achieved at level 1 $\left(20^{\circ} \mathrm{C}\right)$, temperature changes did not have considerable effect on the performance of film coating in reducing the corrosion rate.

As shown in Figure 4, the corrosion rate for the panels decreased upon increasing the mixing time in the preparation process of film coating. It seems that

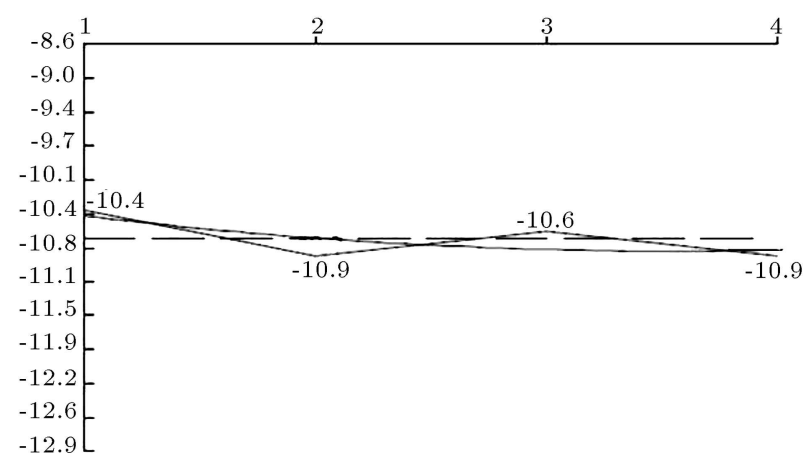

Figure 3. Average of $S / N$ ratio for different levels of temperature used for reducing the corrosion rate. 
Table 5. Optimal levels and contribution of factors in reducing the corrosion rate.

\begin{tabular}{lcccc}
\hline & Factors & Level desc & Level & Contribution \\
\hline 1 & Alumina nanoparticles & 2 & 4 & 0.941 \\
2 & Chitosan nanoparticles & 2 & 4 & 1.122 \\
3 & Temperature & 20 & 1 & 0.301 \\
4 & Mixing time & 30 & 4 & 1.437 \\
\hline
\end{tabular}

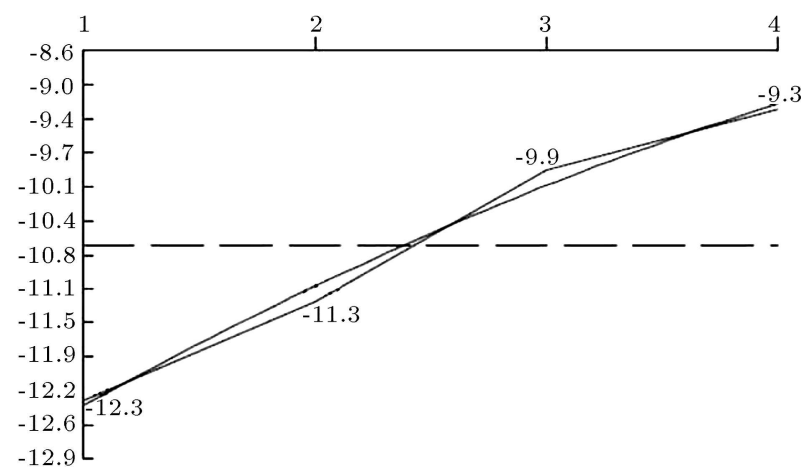

Figure 4. Average of $S / N$ ratio for different levels of mixing time used for reducing the corrosion rate.

the mixing time has the greatest effect on reducing the corrosion rate because the difference between the lowest and highest levels is about $25 \%$. For this factor, the best performance in reducing the corrosion rate for panels was observed at level 4 (30 minutes). The mixing process was enhanced following increase in the mixing time and the whole space of the epoxy matrix was filled with nanoparticles, thus creating a suitable coated film for steel panels so as to prevent the corrosion of steel panels.

The optimal conditions for achieving the highest efficiency in reducing the corrosion rate are presented in Table 5. The optimum concentrations of both alumina nanoparticles and chitosan nanoparticles were measured at $2 \mathrm{wt} \%$. Moreover, the optimum temperature and mixing time were calculated as $20^{\circ} \mathrm{C}$ and 30 minutes, respectively. As illustrated, optimal conditions did not occur in any of the 16 experiments. The steel panel coated with the nanocomposite prepared under optimal conditions was tested, and the corrosion rate of the panel after 30 days was measured as 2.31 (mpy). According to this table, the most effective factor in reducing the corrosion rate is the mixing time. Then, contributions of chitosan nanoparticle concentration, alumina nanoparticle concentration, and temperature had the greatest effect on reducing the corrosion rate in the prepared panels, respectively.

\subsection{The study of prepared nanocomposite by $S E M$}

The most significant application of SEM analysis is the study of morphology and material surface. The prepared coated films were dried and prepared at room

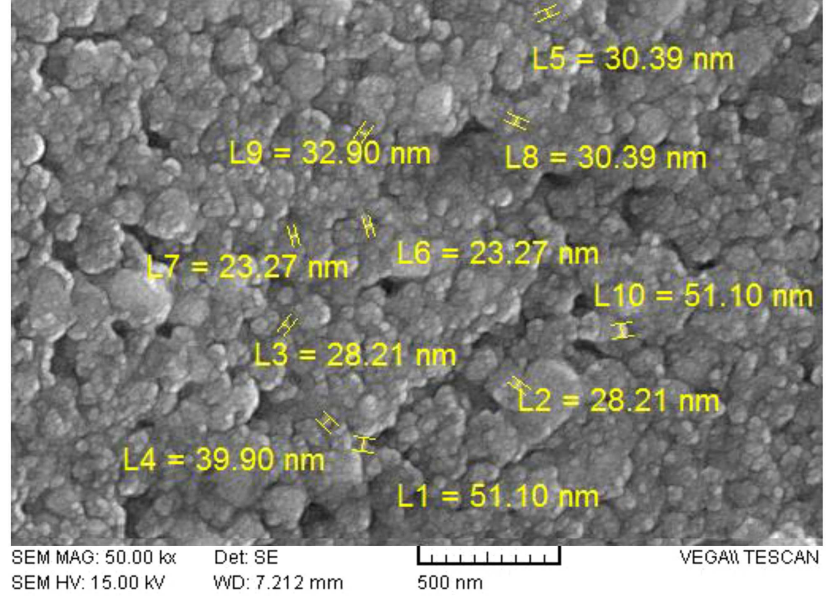

Figure 5. SEM image of film coating in optimal conditions.

temperature after one week. Finally, it was used for SEM analysis. Figure 5 shows the size of alumina and chitosan nanoparticles on the surface of the coated film in the optimal conditions.

\section{Conclusions}

In this study, the anticorrosion properties of epoxybased nanocomposite coating were studied using the Taguchi statistical method. The analysis of variance and signal-to-noise ratio revealed that the nanocomposite-coated steel panels could significantly enhance the anticorrosion properties. The optimal conditions for preparation of film coating comprised alumina nanoparticles $(2 \%)$, chitosan nanoparticles $(2 \%)$, temperature of $20^{\circ} \mathrm{C}$, and a mixing time of 30 minutes. Moreover, the surface of the coated film was analyzed using SEM. Finally, the application of this nanocomposite coating was suggested to prevent metal in different industries.

\section{References}

1. Ghorbani, H.R. and Molaei, M. "Antibacterial nanocomposite preparation of polypropylene-silver using corona discharge", Prog. Org. Coat., 112, pp. 187190 (2017).

2. Deyab, M.A. "Anticorrosion properties of nanocomposites coatings: A critical review", J. Mol. Liq., 313, pp. 113533-113540 (2020). 
3. Ghorbani, H.R. and Molaei, M. "Optimization of coating solution for preparation of antibacterial copperpolyethylene nanocomposite", Mater. Res. Express, 4, p. 065017 (2017).

4. Deyab, M.A. and Guibal, E. "Enhancement of corrosion resistance of the cooling systems in desalination plants by green inhibitor", Sci. Rep., 10, p. 4812 (2020).

5. Abdeen, D.H, Hachach, M.E., Koc, M., et al. "A review on the corrosion behaviour of nanocoatings on metallic substrates", Mater., 12(2), p. 210 (2019).

6. He, Y., Dobryden, I., Pan, J., et al. "Nano-scale mechanical and wear properties of a waterborne hydroxyacrylic-melamine anti-corrosion coating", App. Surf. Sci., 457, pp. 548-558 (2018).

7. Naderi, M., Hoseinabadi, M., Najafi, M., et al. "Investigation of the mechanical, thermal, and anticorrosion properties of epoxy nanocomposite coatings: Effect of synthetic hardener and nanoporous graphene", $J$. Appl. Polym. Sci., 135, pp. 46201-46207 (2018).

8. Samiee, M.R., Ramezanzadeh, B., Mahdavian, M., et al. "Designing a non-hazardous nano-carrier based on graphene oxide@Polyaniline-Praseodymium (III) for fabrication of the active/passive anti-corrosion coating", J. Hazard. Mater., 398, pp. 123136-123143 (2020).

9. Mohammadkhani, R., Ramezanzadeh, M., Saadatmandi, S., et al. "Designing a dual-functional epoxy composite system with self-healing/barrier anticorrosion performance using graphene oxide nanoscale platforms decorated with zinc doped-conductive polypyrrole nanoparticles with great environmental stability and non-toxicity", Chem. Eng. J., 382, pp. 122819-122828 (2020).

10. Liu, Y., Bian, D., Zhao, Y., et al. "Anti-corrosion performance of chemically bonded phosphate ceramic coatings reinforced by nano- $\mathrm{TiO}_{2}$ ", $J$ Mech Behav Biomed Mater, 86, pp. 208-214 (2018).
11. Ahmadi, Z. "Epoxy in nanotechnology: A short review", Prog. Org. Coat., 132, pp. 445-448 (2019).

12. Zheludkevich, M.L., Poznyak, S.K., Rodrigues, L.M., et al. "Active protection coatings with layered double hydroxide nanocontainers of corrosion inhibitor", Corros. Sci., 52, pp. 602-611 (2010).

13. Luo, Y. and Wang, Q. "Recent advances of chitosan and its derivatives for novel applications in food science", J. Food Process. Bev., 1, pp. 13-19 (2013).

14. Alibakhshi, E., Ghasemi, E., Mahdavian, M., et al. "A comparative study on corrosion inhibitive effect of nitrate and phosphate intercalated Zn-Al- layered double hydroxides (LDHs) nanocontainers incorporated into a hybrid silane layer and their effect on cathodic delamination of epoxy topcoat", Corros. Sci., 115, pp. 159-174 (2017).

15. Ghorbani, H.R., Alizadeh, V., Parsa Mehr, F., et al. "Preparation of polyurethane/CuO coating film and the study of antifungal activity", Prog. Org. Coat., 123, pp. 322-325 (2018).

\section{Biographies}

Negin Feizi received her MSc degree in Chemical Engineering from Islamic Azad University, Qaemshahr branch, Iran in 2020. She was at the Faculty of Islamic Azad University, Shahr-e-Qods branch of Chemical Engineering from 2014 to 2018. His research interests are composites, coating, and anticorrosion.

Hamid Reza Ghorbani is an Associate Professor at the Department of Chemical Engineering at Islamic Azad University, Qaemshahr, Iran. His research interests include nanotechnology, nanobiotechnology, nanocomposites, coating, nanofluids, and CFD. He has authored more than 80 scientific papers focusing on the mentioned field of interest. 